\title{
ANALYSIS OF MEDICINAL PROVISION OF PATIENTS WITH ARTERIAL HYPERTENSION IN HOSPITAL CONDITIONS
}

DOI: $10.36740 /$ WLek202103228

\author{
Ivanna V. Sakhanda ${ }^{1}$, Rimma L. Skrypnyk ${ }^{1}$, Kostyantyn L. Kosyachenko ${ }^{1}$, Oleh M. Vlasenko ${ }^{1}$, Anatoliy P. Kazmirchuk ${ }^{2}$ \\ 'BOGOMOLETS NATIONAL MEDICAL UNIVERSITY, KYIV, UKRAINE \\ 2NATIONAL MILITARY MEDICAL CLINICAL CENTRE «THE MAIN MILITARY CLINICAL HOSPITAL», KYIV, UKRAINE
}

\begin{abstract}
The aim: The aim of the study was to study drug consumption in pharmacotherapy of arterial hypertension in a hospital setting.

Materials and methods: In the course of work medical cards of patients of the Kyiv regional Cardiac Dispensary in the conditions of inpatient treatment were used. Methods such as: questionnaire, pharmacoeconomic, expert assessments were used.

Results: One of the main issues of drug supply for the population, in particular for patients with arterial hypertension, is the study of the demand and consumption of drugs. The drugs used to treat hypertension belong to different pharmacotherapeutic groups and are used in the treatment of a number of other diseases. Recent years of development of the domestic pharmaceutical market are characterized by an increase in the number of these drugs.

Conclusions: One of the main issues of drug supply for the population, in particular for patients with arterial hypertension, is the study of the demand and consumption of drugs. As a result of the study, an analysis of the range of drugs for the treatment of hypertension, a comparative study of the market of offers and prices for the treatment of hypertension was carried out.
\end{abstract}

KEY WORDS: arterial hypertension, cardiovascular diseases, marketing research, pharmacotherapy

Wiad Lek. 2021;74(3 p.II):718-721

\section{INTRODUCTION}

An analysis of the range of drugs for the treatment of hypertension, a comparative study of the market offers and prices for the treatment of hypertension [1].

In technologies for the treatment of hypertension, medicines are used today that belong to fourteen pharmacological groups (first-level drugs - diuretics, beta-adrenergic receptor blockers, ACE inhibitors, blockers of alpha-adrenergic receptors, angiotensin II receptors and calcium channels; the second level - agonists of alpha-receptors of the central actions, central and peripheral sympatholytics, vasodilators, potassium channel activators, ganglion blockers, drugs with myotropic action; drugs of a new generation - agonists of imidazoline receptors, calcium ion antagonists and blockers of alpha-1-adrenergic receptors simultaneously), as well as combined drugs. Pharmacological groups of drugs of the first level are recommended for the treatment of arterial hypertension by the World Health Organization $[2,3]$.

\section{THE AIM}

The aim of the study was to study drug consumption in pharmacotherapy of arterial hypertension in a hospital setting.

\section{MATERIALS AND METHODS}

The base of the experimental study was the Cardiological Dispensary of the Kyiv Health Department. Subjects of research - medical records, which were selected by the method of free sampling. A total of 1038 case histories were analyzed for 2019 .

\section{RESULTS}

Each case history was analyzed according to the following criteria: the name, sex and age of the patient, the stage of arterial hypertension, the length of stay of the patient in the hospital, concomitant diseases, the appointment of a cardiologist, the cost of pharmacotherapy [4, 5]. Microsoft Excel spreadsheets were used for mathematical data processing.

As can be seen from Table I, 12,5 \% of case histories belonged to the first stage of arterial hypertension, 71,2 $\%$ to the second, $20,1 \%$ to the third. More than half of all patients were women. The average age of the patients was $42,6,50,2$ and 52,1 years in accordance with the stages of the disease. A similar trend is observed for the average length of hospital stay. At the same time, the deadlines (4 and 30 days) are typical for patients with the first and second stages of arterial hypertension, respectively. For half of the patients, hypertension was characterized by a crisis course. On average, during the treatment period, one patient of the first stage of arterial hypertension was prescribed 9,4 drugs, the second - 12,3 and the third 10,7 . The studied nomenclature of drugs prescribed by cardiologists amounted to 107 drugs in the form of 118 trade names, the total index of occurrences of which in the 
Table I. Quantitative characteristics of case histories

\begin{tabular}{|c|c|c|c|c|c|}
\hline \multirow{2}{*}{ № } & \multirow{2}{*}{ Indicators } & \multicolumn{3}{|c|}{ Stage of arterial hypertension } & \multirow{2}{*}{ Total } \\
\hline & & First & Second & Third & \\
\hline \multirow[t]{2}{*}{1.} & The number of case histories & 125 & 712 & 201 & 1038 \\
\hline & - incl. in \% & 12,5 & 71,2 & 20,1 & 100,0 \\
\hline \multirow[t]{3}{*}{2.} & \multicolumn{5}{|c|}{ Patient gender, in \%: } \\
\hline & - female & 62,1 & 55,8 & 52,2 & 56,7 \\
\hline & - male & 37,9 & 44,2 & 47,8 & 43,3 \\
\hline \multirow[t]{4}{*}{3.} & \multicolumn{5}{|c|}{ Patient's age, in years: } \\
\hline & - minimum & 21 & 37 & 49 & 36 \\
\hline & - maximum & 71 & 74 & 75 & 73 \\
\hline & - middle & 42,6 & 50,2 & 52,1 & 48,3 \\
\hline 4. & Number of days of hospital stay & 1625 & 10228 & 2427 & 14280 \\
\hline \multirow[t]{4}{*}{5.} & \multicolumn{5}{|c|}{ Length of stay of one patient in the hospital, days: } \\
\hline & - minimum & 8 & 11 & 16 & 12 \\
\hline & - maximum & 21 & 25 & 23 & 23 \\
\hline & - middle & 10,8 & 13,6 & 15,8 & 13,4 \\
\hline 6. & The incidence index of concomitant diseases, units & 425 & 3475 & 1278 & 5178 \\
\hline \multirow[t]{4}{*}{7.} & \multicolumn{5}{|c|}{ The number of concomitant diseases per patient, units: } \\
\hline & - minimum & 1 & 2 & 3 & 2 \\
\hline & - maximum & 8 & 14 & 11 & 11 \\
\hline & - middle & 4,0 & 4,5 & 5,8 & 4,8 \\
\hline 8. & The total number of medical appointments, units & 1247 & 8201 & 1170 & 10618 \\
\hline \multirow[t]{4}{*}{9.} & \multicolumn{5}{|c|}{ The number of prescribed drugs for one patient, units: } \\
\hline & - minimum & 4 & 5 & 6 & 5 \\
\hline & - maximum & 17 & 21 & 20 & 19 \\
\hline & - middle & 9,4 & 12,3 & 10,7 & 10,8 \\
\hline 10. & $\begin{array}{l}\text { The total cost of pharmacotherapy for a certain sample of } \\
\text { patients, UAH }\end{array}$ & 12047,50 & 62247,20 & 20142,30 & 94437,0 \\
\hline \multirow[t]{4}{*}{11.} & The total cost of pharmacotherap & a certain sa & f patients, & & \\
\hline & - minimum & 31,20 & 55,40 & 29,45 & 38,68 \\
\hline & - maximum & 185,40 & 248,20 & 294,50 & 242,70 \\
\hline & - middle & 82,50 & 98,40 & 90,55 & 90,48 \\
\hline 12. & $\begin{array}{l}\text { Correlation coefficient between the length of stay and the } \\
\text { cost of pharmacotherapy per patient }\end{array}$ & 0,57 & 0,69 & 0,50 & 0,59 \\
\hline
\end{tabular}

case histories was 10618. Antihypertensive drugs account for $34,8 \%$ of all medical prescriptions. In general, in the structure of antihypertensive drugs prescribed to patients, diuretics accounted for $32,5 \%$, calcium channel blockers $-16,4 \%$, ACE inhibitors - $15,7 \%$, drugs with myotropic action $-12,7 \%$, combined drugs $-8,1 \%$, beta-blockers $6,3 \%$, central alpha-adrenergic receptors $-4,9 \%$, ganglion blockers $-3,4 \%$.

In total, the doctors of the cardiological dispensary prescribed 20 antihypertensive drugs (by international names) in the form of 29 trade names. The dominant group (75\% of medical prescriptions) among medicines (by international names) consisted of eight drugs (that is, 31,6 $\%$ of their total number), namely: furosemide (diuretic), diltiazem (calcium channel blocker), enalapril (inhibitor ACE), bendazole (myotropic effect), triamterene + hydrochlorthiazide (combined diuretic), atenolol (beta-blocker), hydrochlorthiazide (diuretic), clonidine (central alpha-adrenergic receptor). The most popular antihypertensive drugs by trade names are: dibazol (myotropic action), triampur compositum (combined diuretic), diltiazem (calcium channel blocker), lasix and furosemide (diuretics), atenolol (beta-blocker), cortiazem retard (calcium channel blocker), enalapril and enap (ACE inhibitors), hypothiazide (diuretic) and clonidine (central alpha-adrenergic receptor). The drugs listed above (19,4\% of the total number of trade names) constitute the dominant group of trade marks that are used in antihypertensive therapy. 
In the process of determining the cost indicators, the number of units of the drug (tablets, drops, etc.), which were prescribed to the patient during his stay in the hospital, was first established, and then its cost was established. Calculations have shown (table 1) that the cost of pharmacotherapy for one patient with arterial hypertension (stage 1) is on average UAH 82,50 with a range of variation from 31,20 to $185,40 \mathrm{UAH}$. For the second stage, the average cost was 25,3 $\%$ higher and amounted to UAH 98,40 with a range of variation from UAH 55,40 to 248,20. The final stage of the study was a comparative analysis of the list of drugs prescribed by inpatient cardiologists and the restrictive List of drugs allowed for purchase by State Medical Institutions. The results of the analysis showed that of the 118 assigned funds, $38,2 \%$ were not included in the restrictive List. They were prescribed to patients in 29,6\% of cases and on average accounted for 32,2\% of the cost of pharmacotherapy per patient.

\section{DISCUSSION}

The experience of European countries shows that the solution to the issue of providing the population with quality and affordable drugs is in the sphere of influence of the formulary system of medicines as a component of industry standards in the field of health care. Works are devoted to the methodological principles of creating a formulary system at the state level, its organizational features V.I. Maltsev, A.M. Morozov, V.D. Parii et al.; A.B. Zimenkovskyi et al. Given the rather dynamic development of pharmacy in recent years, changes in society in all countries, we believe that the future of pharmacy, its development as part of the pharmaceutical supply system, as well as its interdisciplinary and intersectoral nature, are closely linked to changes in socio-economic, political, cultural and educational life of Ukraine. According to a modern model of hypertension management, the patient and not his/her disease has a central role and is directly involved in his/her health care management in collaboration with the physician, family, and community, each other interacting in different ways to influence and support health decision [6]. This approach also emphasizes that patients with the same disease are nonetheless different from one another, due to differences in genetic predisposition as well as underlying mechanisms for high BP. Thus, different subjects may respond differently to the same antihypertensive treatment and a traditional population-based approach may not be effective. Rather an individualized or personalized approach is required, according to a modern medical model often referred to as "precision medicine» [7]. This article has summarised the current evidence related to hypertension screening and management in community pharmacies. The strongest evidence in support of pharmacist involvement relates to their role in managing hypertension, where meta-analyses have suggested that BP can be significantly reduced by up to $7 \mathrm{mmHg}$ over usual GP care. Despite this, there are a lack of economic analyses and "hard outcomes» (e.g. CV events) that would likely aid the translation of the existing evidence from trial settings into real-world practice. Our results showed that the number of types of antihypertensive drugs was larger in hospitals equipped with $\geq 200$ beds than in smaller facilities, and the proportion of patients who were prescribed $>2$ antihypertensive drugs was the same. The difference showed statistical significance, indicating the association between facility size and the intensity of hypertension therapy. This result might indicate that the patients with difficult-to-control hypertension, to some extent, visit larger, experienced facilities, but the difference was not so large. First, the database used in this study only contained administrative data, and no blood pressure or chemical examination data were available. Therefore, we could not extract adequate outcomes or comorbidities from the viewpoint of pathophysiology, but could only estimate them from prescription and diagnosis data. Financial incentives for reimbursement and governmental punishment for overcharge may make the prescription data accurate, but the association between prescription claim and patient conditions has not yet been proven. Regarding diagnosis information related to kidney disease, as also mentioned in the discussion section, its sensitivity was reported to be low. Therefore, information related to these strata is limited. Second, we could not distinguish physicians' intention of prescription other than lowering blood pressure. For instance, we could not omit beta-blocker prescription for heart failure or diuretics for hypervolemia. Owing to this limitation, the mean number of antihypertensive agents increased, and the proportion of refractory hypertension also increased. Finally, the data obtained were those accumulated in only one month, October. We could not take seasonal effects into account, and we might have missed patients whose hypertension was managed but did not visit a healthcare facility during this month. In addition, the consultation interval can be different between large hospitals and clinics due to the difference in background comorbidities, which were not adjusted for in the aforementioned stratification. Therefore, this variation in consultation interval may have also affected our results. Ideally, our investigation would be more accurate when utilizing the whole claims data from the ministry. However, restricting laws and regulations are far stronger if we intend to use the whole data compared to the sampled data that we analyzed in the present study. To effectively examine the current healthcare situation, our method has certain rationality even though some limitations exist [8].

\section{CONCLUSIONS}

Thus, on average, more than half of the cost of pharmacotherapy for one patient with arterial hypertension, including more than three quarters of the cost of antihypertensive drugs, was provided not at the expense of state guarantees of free medical care, but in other ways. This is the purchase of the necessary medicine by the patient himself or his family. 


\section{REFERENCES}

1. Gorgui J., Gorshkov M. et al. Hypertension as a risk factor for ischemic stroke in women. The Canadian journal of cardiology. 2014;30(7):774-782.

2. Drummond M.F., O'Brien B., Stoddart K. Methods for the economic evaluation of health care programmers. 2012;78(2):92-116.

3. Apazov A.D. Legislative and economic foundations for the formation of a civilized pharmaceutical market. New pharmacy. 2011;12:9-12.

4. Gromovik B.P. Characteristics of the main methods of determining the competitiveness of medicines. Pharmaceutical Journal. 2012;3:7-11.

5. Sakhanda I.V. Analysis of assortment of phytopreparations in Ukraine. Harkiv: 2017;46-49.

6. Carter B.L., Bosworth H.B., Green B.B. The hypertension team: the role of the pharmacist, nurse, and teamwork in hypertension therapy. J Clin Hypertens. 2012;14:51-65.

7. Melville S., Byrd J.B. Personalized medicine and the treatment of hypertension. Curr Hypertens Rep. 2019;21:13.

8. Sakamoto H.R.M., Nomura S., Okamoto E. et al. 5.3.1 Primary care. In: Japan Health System Review. Vol 8. New Delhi: World Health Organization, Regional Office for South-East Asia; 2018.

This work was carried out in the framework of the research work «Organizational and technological research of medicinal and cosmetic products» (2018-2020, registration number № 0114U001826).

\section{ORCID and contributionship:}

Ivanna V. Sakhanda: 0000-0003-4171-5160 ${ }^{A, B, C, D}$

Rimma L. Skrypnyk: 0000-0002-9175-2683 E,F

Kostyantyn L. Kosyachenko: 0000-0002-0472-2196 ${ }^{A, C, D}$

Oleh M. Vlasenko: 0000-0001-6697-2150 A,E

Anatoliy P. Kazmirchuk: 0000-0002-6020-2697 ${ }^{\mathrm{A}}$

\section{Conflict of interest:}

The Authors declare no conflict of interest.

\section{CORRESPONDING AUTHOR}

\section{Ivanna V. Sakhanda}

Bogomolets National Medical University

13 Taras Shevchenko Boulevard, 01601 Kyiv, Ukraine

tel: +380991943687

e-mail: sahanda.ivanna@ukr.net

Received: 15.12 .2020

Accepted: 04.03.2021

A - Work concept and design, B - Data collection and analysis, C - Responsibility for statistical analysis,

D-Writing the article, $\mathbf{E}$-Critical review, $\mathbf{F}$ - Final approval of the article 